\title{
Long-Term Anatomic and Visual Outcome Following Vitrectomy for Stage 4B and 5 Retinopathy of Prematurity
}

Elena Gusson, MD; Francesca Bosello, MD; Francesca Allegrini, MD; Lucia Firolli, MD; Ilaria Tomaello, MD; Giorgio Marchini, MD; Rocco Micciolo, MD; Silvia Pignatto, MD; Antonio Capone Jr., MD

BACKGROUND AND OBJECTIVES: Surgical indications in stages $4 \mathrm{~B}$ and 5 retinopathy of prematurity (ROP) are not universally accepted. The authors' purpose is to evaluate the long-term anatomic and visual outcomes of vitrectomy for retinal detachment (RD) associated with stages $4 \mathrm{~B}$ and 5 ROP.

PATIENTS AND METHODS: Data of patients who consecutively underwent vitrectomy for stages $4 \mathrm{~B}$ and 5 ROP from 1999 to 2013 were retrospectively reviewed and included grade of retinal attachment and visual acuity (VA) at the last follow-up.

RESULTS: Seventy eyes of 38 infants were included: 23 with stage $4 \mathrm{~B}$ and 47 with stage 5 ROP. Lenssparing vitrectomy was performed in 11 eyes, combined lensectomy / vitrectomy in 59 eyes. Mean follow-up was 8.5 years. Anatomic success was maintained in 41 eyes (58.5\%), and among them, VA greater than $5 / 200$ was achieved in 17 eyes $(41.4 \%)$.

CONCLUSION: The long-term visual and anatomic success rates were encouraging for the surgical correction of $\mathrm{RD}$ associated with late stages $\mathrm{ROP}$.

[Ophthalmic Surg Lasers Imaging Retina. 2019;50:208-214.]

\section{INTRODUCTION}

Retinopathy of prematurity (ROP) is a retinal vascular disorder that is among the leading causes of blindness for children in developed countries. ${ }^{1}$ The overall ROP incidence has remained relatively stable during the last few decades despite the increasing proportion of the most at-risk population of infants. ${ }^{2}$ Currently, laser ablation of the avascular retinal periphery remains the gold standard treatment for type 1 ROP. ${ }^{3}$ Despite timely and appropriate laser treatment, approximately $12 \%$ of eyes progress to retinal detachment (RD). ${ }^{4}$

The benefits in the surgical management of stage 4A have been demonstrated by several authors and are generally accepted. ${ }^{5}$ However, the practical utility of surgery for stage $4 \mathrm{~B}$ and 5 ROP remains a matter of debate. ${ }^{6}$ Though several published series seem to demonstrate the efficacy of vitreoretinal surgery for stages $4 \mathrm{~B}$ and $5,,^{7-9}$ surgical indications are not universally accepted, management approaches vary widely, and long-term anatomic and visual outcome data are lacking. This large case series of 70 eyes with stage 4B and 5 ROP operated upon and followed for a mean time of 8.5 years describes the long-term impact of surgery in advanced stages of ROP.

\section{PATIENTS AND METHODS}

This is a retrospective study of patients affected by stage $4 \mathrm{~B}$ and $5 \mathrm{ROP}$, inborn or referred, at the Pediatric Ophthalmic Unit of the University of Verona, Italy, from 1999 to 2013.

\footnotetext{
From Eye Clinic, Department of Neurosciences, Biomedicine and Movement, University of Verona, Verona, Italy (EG, FB, FA, LF, IT, GM); the Department of Psychology and Cognitive Sciences, University of Trento, Trento, Italy (RM); the Department of Medical and Biological Sciences- Ophthalmology, University of Udine, Udine, Italy (SP); and the Department of Ophthalmology, William Beaumont Hospital, Royal Oak, Michigan (AC).
}

Originally submitted June 13, 2018. Revision received June 13, 2018. Accepted for publication November 5, 2018.

Presented in part at VitReEx (Vitreo-Retinal Experience), Rovigo, Italy, February 3, 2017.

The authors report no relevant financial disclosures.

Address correspondence to Elena Gusson, MD, Piazzale Stefani 1, Verona, Italy 37121; email: elena.gusson@aovr.veneto.it. doi: 10.3928/23258160-20190401-02 


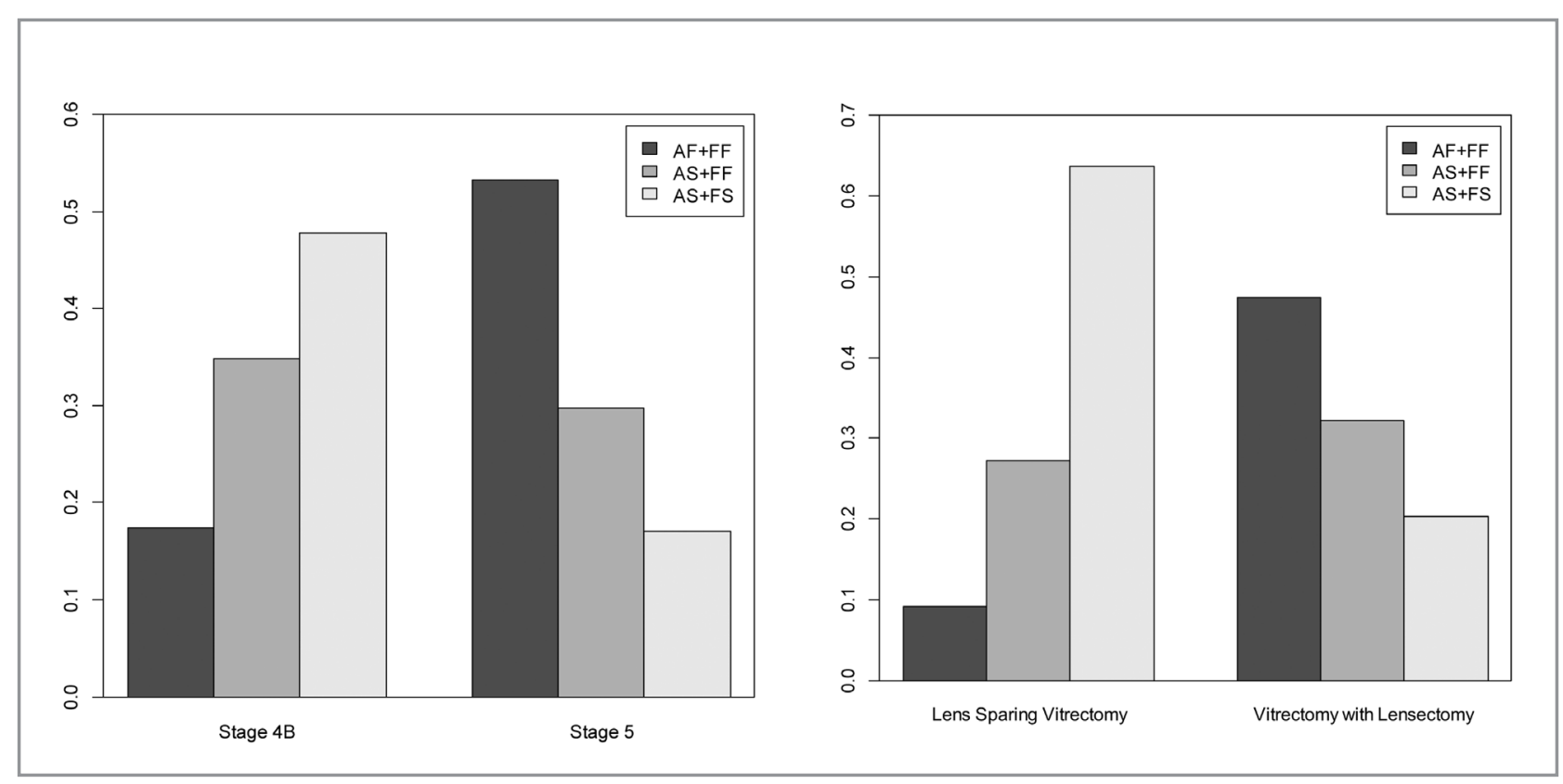

Figure 1. Distribution of the three different combined anatomic and functional outcomes according to retinopathy of prematurity stage (left panel) and to the type of surgical intervention (right panel). (a) AF+FF: anatomic failure + functional failure. (b) AS+FF: anatomic success + functional failure. (c) AS+FS: anatomic success + functional success.

By virtue of a collaboration between our department and Associated Retinal Consultants / William Beaumont Hospital, a recognized referral center for advanced pediatric vitreoretinal surgery in the United States, parents of the infants were offered vitreoretinal surgical intervention at this hospital. All infants underwent surgery by a sole experienced pediatric vitreoretinal surgeon (AC) and received preoperative and postoperative care by two pediatric ophthalmologists (EG and SP).

Written informed consent was obtained from parents or legal guardians of all infants before examinations under anesthesia and vitreoretinal surgical interventions were performed in agreement with the tenets of the Declaration of Helsinki. Our institutional review board approved the study.

We reviewed the following data: gestational age and weight at birth, the stage of ROP at the time of surgical intervention, surgery performed, final anatomical and visual outcomes, diagnosis of leukomalacia (by MRI), and ocular complications.

The surgery performed was a lens-sparing vitrectomy (LSV) ${ }^{10}$ or vitrectomy with lensectomy (LV), surgical techniques previously described by Trese. ${ }^{11}$ If the lens was found to limit adequate intraoperative visualization or to interfere with the management of traction, a lensectomy was performed.

After the early postoperative evaluations, all patients underwent regular examination at a maximum of every 6 months under general anesthesia or deep sedation, depending on age and patient cooperation. Retinal status was analyzed by indirect ophthalmoscopy. Anatomical success at the final visit was defined as the retina successfully reattached at least in zone 1 (a circle with a radius extending from the optic nerve to double the distance to the macula). Eyes that were detached in zone 1 but had a portion of peripheral retina attached at the last follow-up were defined as "partially attached" and not included in the anatomic success group due to the insufficient functional benefit of this type of anatomic result.

Visual function measurements were graded as "no light perception (NLP), "light perception," "form vision," "low vision cards" (Teller cards), and "better than low vision cards" (Snellen acuity chart). If light perception was uncertain due to developmental delay and neurologic abnormalities, patients underwent visual evoked potential. Orthoptic evaluation and low vision rehabilitation were provided with the aim of optimizing visual development. Contact lenses or eyeglasses were prescribed to correct aphakia and refractive errors. Successful visual outcome was considered the achievement of a visual acuity (VA) better than form vision, which corresponds to an ambulatory vision, necessary condition for the patient to ambulate safely in the environment. ${ }^{5}$ Lower functional outcomes were considered failure outcomes. 
TABLE 1

Long-Term Anatomic Outcome of Vitrectomy for Treatment of Retinal Detachment of Premature Infants According to Selected Variables

\begin{tabular}{|c|c|c|c|c|c|}
\hline & & \multicolumn{4}{|c|}{ Anatomic Outcome } \\
\hline & & Success & Failure & $\%$ Success & $P$ Value \\
\hline \multirow[t]{2}{*}{ ROP Stage } & $4 b$ & 19 & 4 & 82.6 & .005 \\
\hline & 5 & 22 & 25 & 46.8 & \\
\hline \multirow[t]{2}{*}{ Type of Surgery } & LV & 31 & 28 & 52.5 & .021 \\
\hline & LSV & 10 & 1 & 90.9 & \\
\hline \multirow[t]{2}{*}{ Previous Surgery } & Yes & 14 & 14 & 50.0 & .322 \\
\hline & No & 27 & 15 & 64.3 & \\
\hline \multirow[t]{2}{*}{ Leukomalachia } & Yes & 15 & 14 & 51.7 & .460 \\
\hline & No & 26 & 15 & 63.4 & \\
\hline
\end{tabular}

Success: retina attached at least in zone 1; Failure: peripheral retina attached or completely detached retina.

$R O P=$ retinopathy of prematurity $\angle V=$ vitrectomy with lensectomy; $L S V=$ lens-sparing vitrectomy

Statistical analysis was performed employing Fisher's exact test that gives exact $P$ value for comparing proportions and logistic regression combined with the likelihood ratio test (LRT) to perform adjusted analyses. The odds ratio was used as a measure of "size effect."

\section{RESULTS}

Seventy consecutive eyes of 38 patients, 20 males and 18 females, were included. The mean follow-up was 8.5 years (range: 2 years to 16 years). The mean gestational age at birth was 26 weeks (range: 23 weeks to 29 weeks). The mean birth weight was 725 grams (range: 540 grams to 1,215 grams). Retinal ablative treatment had been performed for stage 3 threshold or high-risk pre-threshold ROP on 66 eyes (57 eyes by laser retinopexy and nine eyes by cryopexy) prior to the progression of ROP. Peripheral retinal ablation was not performed on four eyes $(5.7 \%)$ of outborn infants. None of these patients had previously undergone intravitreal anti-vascular endothelial growth factor injection.

The mean uncorrected age at the time of vitreoretinal surgery was 11 months (range: 5 months to 18 months). LV was carried out on 59 eyes (84.3\%): 17 eyes with stage $4 \mathrm{~B}(28.8 \%)$ and 42 with stage 5 $(71.2 \%)$. LSV was performed on the remaining 11 eyes (15.7\%): five with stage 5 ROP and six with stage 4B ROP. The percentages of LSV procedures performed in stage $4 \mathrm{~B}(54.5 \%)$ and in stage $5(45.4 \%)$ were not significantly different (Fisher's exact test; $P=.159$ ).

Some eyes underwent more than one procedure to achieve retinal reattachment. Twenty-six of 70 eyes $(37.1 \%)$ underwent two procedures (Italy and the U.S.), and two eyes (4.3\%) underwent three procedures (Italy and the U.S.)

\section{Anatomic Outcomes}

Anatomic success was achieved after surgery and maintained at the last follow-up in 41 eyes $(58.6 \%)$ overall (Table 1). Stage of progression of ROP at the time of surgery was significantly associated with the anatomic success and was achieved in $82.6 \%$ of eyes with stage $4 \mathrm{~B}$ and $46.8 \%$ with stage $5(P=.005)$ with an odds ratio of 5.40 .

A significant difference in the percentage of long-term anatomic success was found also comparing the surgical technique LV to LSV $(P=.021)$ with an odds ratio of 9.03 .

The significantly better outcomes observed with LSV were also confirmed when the ROP stage was taken into account; the stage-adjusted odds of an anatomic success were more than seven-times higher in LSV than in LV operated eyes (LRT test $=4.75$; $P=.029$ ).

Long-term anatomic success was not significantly associated with either multiple procedures $(P=.322)$ or with leukomalachia $(P=.460)$.

\section{Functional Outcomes}

The functional outcomes (Table 2) have been grouped in "better than form vision" (successful outcome) or lower (failure) according to selected variables (Table 3).

Functional success was recorded in 19 eyes, and a significant difference $(P=.010)$ was found 
TABLE 2

Number (N) and Percentage (\%) of Subjects According to Functional Outcome and ROP Stage

\begin{tabular}{l|l|l|l|l}
\hline & \multicolumn{2}{l|}{ Stage 4B } & Stage 5 \\
\hline Functional Outcome & $\mathbf{N}$ & \% & $\mathbf{N}$ & \% \\
\hline No light perception & 4 & 17.4 & 2 & 4.3 \\
\hline Light perception & 6 & 26.1 & 5 & 10.6 \\
\hline Forms perception & 1 & 4.3 & 1 & 2.1 \\
\hline Low vision cards & 9 & 39.1 & 25 & 53.2 \\
\hline$>$ Low vision cards & 3 & 13.0 & 14 & 29.8 \\
\hline Total & 23 & 100 & 47 & 100
\end{tabular}

$R O P=$ retinopathy of prematurity

between stage $4 \mathrm{~B}(47.8 \%)$ and stage $5(17 \%)$, with an odds ratio of 4.47 .

A significant difference in the percentage of longterm functional success was found also between the eyes operated with LV and those operated with LSV $(P=.007)$, with an odds ratio of 6.85 . The significantly better outcomes observed with LSV were also confirmed when the ROP stage was taken into account; the stage-adjusted odds of a VA better than form vision were about six-times higher in LSV than in LV operated eyes (LRT test $=5.78 ; P=.016$ ). Long-term functional success was negatively correlated with both multiple surgeries $(P=.424)$ and leukomalacia $(P=.415)$.

\section{Combining Anatomic and Functional Outcomes}

Anatomic and functional outcomes have been combined in a new categorical variable with three levels, according to the previous definition of anatomic and functional success / failure. The combined data have been distributed according to ROP stage (Figure 1, left panel) and surgery performed (Figure 1, right panel). The percentage of both anatomic and functional success achieved was higher in stage 4B $(47.8 \%)$ than in stage $5(17.0 \%)$, whereas the percentage of both anatomic and functional failure achieved was lower in stage $4 \mathrm{~B}(17.4 \%)$ than in stage $5(53.2 \%)$. These differences were highly significant (Fisher's exact test; $P=.005)$. The percentage of both anatomic and functional success achieved was higher in LSV (63.6\%) than in LV operated $(20.3 \%)$, whereas the percentage of both anatomic and functional failure achieved was lower in LSV (9.1\%) than in LV operated (47.5\%). These differences were highly significant (Fisher's exact test; $P=.006$ ).

The significantly better outcomes observed with LSV with respect to LV were confirmed also when the ROP stage was taken into account (LRT test = 7.31; $P=.026)$. The distribution of the combined anatomic and functional outcomes was not significantly different between eyes previously operated in Italy and eyes operated only in the U.S. (Fisher's exact test; $P=.527$ ), nor between patients with and without leukomalacia (Fisher's exact test, $P=.536$ ).

\section{Complications}

During follow-up, intraocular hemorrhage occurred in six eyes (8.6\%), corneal opacity in three eyes $(4.3 \%)$, and phthisis in five eyes $(7.1 \%)$.

Glaucoma occurred in 10 eyes $(14.3 \%)$, nine of which had undergone LV. Glaucoma occurred bilaterally in three children, none of whom had function better than light perception, even if the retina was successfully attached. Only two eyes had functional results greater than or equal to that of the low vision cards. All the cases of glaucoma occurred more than 3 years after surgery. Only one case required surgery (Baerveldt tube implant; Johnson \& Johnson, New Brunswick, NJ).

Long-term complications were more common in eyes without retinal attachment $(76 \%)$.

\section{DISCUSSION}

The management of RD in advanced stages of ROP remains controversial. Comparison of anatomic success data from published series (Table 4) is challenging, in large part because the International Classification of Retinopathy of Prematurity inadequately addresses the complex and variable anatomy of advanced ROP. ${ }^{12}$ Consequently, literature is plagued by a lack of uniformity, making comparison between series difficult; whether an eye with advanced ROP (stage 4A / 4B or 5) had or not been treated with either cryopexy or laser, the timing of 


\begin{tabular}{|c|c|c|c|c|c|}
\hline \multicolumn{6}{|c|}{$\begin{array}{c}\text { TABLE } 3 \\
\begin{array}{c}\text { Long-Term Visual Outcome of Vitrectomy for Treatment of Retinal Detachment of } \\
\text { Premature Infants According to Selected Variables }\end{array}\end{array}$} \\
\hline & & \multicolumn{4}{|c|}{ Visual Outcome } \\
\hline & & Success & Failure & $\%$ Success & $P$ Value \\
\hline ROP Stage & $\begin{array}{l}4 \mathrm{~B} \\
5\end{array}$ & $\begin{array}{l}11 \\
8\end{array}$ & $\begin{array}{l}12 \\
39\end{array}$ & $\begin{array}{l}47.8 \\
17.0\end{array}$ & .010 \\
\hline Type of Surgery & \begin{tabular}{|l} 
LV \\
LSV
\end{tabular} & $\begin{array}{l}12 \\
7\end{array}$ & $\begin{array}{l}47 \\
4\end{array}$ & $\begin{array}{l}20.3 \\
63.6\end{array}$ & .007 \\
\hline Previous Surgery & $\begin{array}{l}\text { Yes } \\
\text { No }\end{array}$ & \begin{tabular}{|l|}
6 \\
13
\end{tabular} & $\begin{array}{l}22 \\
29\end{array}$ & $\begin{array}{l}21.4 \\
31.0\end{array}$ & .424 \\
\hline Leukomalachia & $\begin{array}{l}\text { Yes } \\
\text { No }\end{array}$ & \begin{tabular}{|l|}
6 \\
13
\end{tabular} & $\begin{array}{l}23 \\
28\end{array}$ & $\begin{array}{l}20.7 \\
31.7\end{array}$ & .415 \\
\hline \multicolumn{6}{|c|}{ Success $=$ visual acuity better than form vision; Failure $=$ lower than form vision; $P=$ exact $P$ value } \\
\hline
\end{tabular}

surgery with regard to vascular activity or the age of the infant at surgery, the precise anatomy of detachments, whether subretinal blood is present and to what extent, and the presence and severity ocular and systemic comorbidities are key features that vary between series.

The consistency of the pediatric ophthalmology caregivers and single-surgeon management approach are distinguishing elements of the current study. For organizational and travel requirements, the age of patients at the time of surgery was never under the postnatal age of 5 months (with an average of 11 months). Nevertheless, our anatomical results are encouraging as compared to the ETROP study, ${ }^{5}$ wherein among 10 eyes that underwent vitrectomy, only six of 10 with stage $4 \mathrm{~B}$ ROP and zero of 10 eyes with stage 5 ROP maintained anatomic success at the long-term evaluation. Admittedly, the ETROP was not designed to evaluate the utility of surgery in the management of advanced ROP.

Functional outcomes are also extremely difficult to compare between published series ,7-9,13-17 $^{5}$ Table 4) due to variability in the extent to which visual rehabilitation was pursued and diverse approaches to assessing vision. In our series, $46.3 \%$ of eyes with anatomic success after vitrectomy could maintain an "ambulatory vision," 5 and this supported a positive correlation between anatomic outcome and visual function. An NLP outcome was uncommon among eyes with anatomic success: $0 \%$ for stage $4 \mathrm{~B}$ and $9.1 \%$ for stage 5 ROP eyes, respectively. In the literature (Table 4), ${ }^{4,8,9,16,18-21}$ poor visual outcomes have been reported in most cases of advanced ROP stages, even if retinal reattachment is achieved after surgery, especially for stage 5 .

Lack of visual function in the presence of anatomic success could be explained by non-ocular visual pathway damage related to complications of extreme prematurity. ${ }^{22}$ The impact of RD and subsequent reattachment on the developing photoreceptor-retinal pigment epithelial complex may also explain the poor visual function despite retinal reattachment. These results reinforce the tenet that maximal efficacy derives from efforts directed toward preventing RD. ${ }^{21}$

There is robust support in the literature on latestage ROP surgery for superior anatomic and, consequently, functional outcome of LSV compared to LV. ${ }^{8,9,13,23}$ Clearly a phakic eye will fare better, all other things being equal. However, the lens is not spared at the expense of a less effective posterior segment intervention, as when fibrovascular tissue extends toward the vitreous base and reaches the ciliary body and / or the posterior lens surface. ${ }^{24}$ Surgical removal of the vitreous framework, by reducing tractional force on the fibrovascular tissue, may suppress new vessel growth activated by the traction. ${ }^{25}$ The decision to perform lensectomy in infants with complex ROP-related RDs has long-term implications, particularly regarding the management of aphakia and the increased lifetime risk of aphakic glaucoma, ${ }^{26,27}$ the pathogenesis of which remains to be clearly elucidated. It has been hypothesized that early lensectomy may interfere 
TABLE 4

Long-Term Efficacy of Surgery for Advanced Stages of Retinopathy of Prematurity

(Stages 4B / 5)

\begin{tabular}{|c|c|c|c|c|c|c|}
\hline Authors & $\begin{array}{l}\text { Follow- } \\
\text { Up } \\
\text { (Years) }\end{array}$ & $\begin{array}{l}\text { No. of } \\
\text { Eyes } \\
\text { ROP } \\
\text { 4B / } 5\end{array}$ & $\begin{array}{l}\text { Eyes } \\
\text { With Any } \\
\text { Attachment } \\
\text { (\%) ROP } \\
\text { 4B / } 5\end{array}$ & $\begin{array}{l}\text { Mean VA > LP } \\
\text { (\% of Eyes) } \\
\text { ROP 4B / } 5\end{array}$ & $\begin{array}{l}\text { NLP ( } \% \text { of } \\
\text { eyes) } \\
\text { ROP 4B / } 5\end{array}$ & $\begin{array}{l}\text { Percentage of } \\
\text { Complications } \\
\text { (Vitreous } \\
\text { Hemorrhage, Corneal } \\
\text { Opacity, Glaucoma) }\end{array}$ \\
\hline Karacorlu $^{13} 2016$ & 6.9 & $38 / 31$ & $63 / 42$ & $58 / 35$ & $26(18 / 69)$ & NS, 13 / 19, 8 / 29 \\
\hline Gadkari $^{14} 2015$ & 0.5 & $20 / 11$ & $90 / 45$ & 71 overall & $29(9 / 31)$ & NS, NS, NS \\
\hline Choi $^{9} 2011$ & 5.6 & $13 / 8$ & $62 / 13$ & 78 of attached & $47(10 / 21)$ & $43,29,33$ \\
\hline Shah $^{15} 2009$ & 1.6 & $9 / 14$ & $44 / 14$ & NS & NS & NS, NS, NS \\
\hline$W_{u^{7}} 2008$ & 4 & $-/ 80$ & $-/ 69$ & 81 & 14 & NS, $7.5,7.5$ \\
\hline El Rayes ${ }^{8} 2008$ & 3 & $56 /-$ & $73.2 /-$ & 97.4 & 0 & NS, NS, 31 \\
\hline Fuchino $^{16} 1995$ & NS & $-/ 49$ & $-/ 59$ & 95 of attached & 5 & NS, NS, NS \\
\hline Seaber ${ }^{1} 1995$ & 5.1 & $-/ 51$ & 25 & 78 of attached & 15 & NS, 14,6 \\
\hline Trese $^{17} 1998$ & 3.7 & $16 / 16$ & $83 / 50$ & $78 / 63$ & $18 / 37$ & NS, NS, NS \\
\hline
\end{tabular}

with maturation of the trabecular meshwork, ${ }^{26,28}$ confirmed by alterations found on gonioscopy, such as flat iris insertion and poorly developed angle recess. ${ }^{29}$ Examination under anesthesia at 6 months interval is often necessary given that the infants are not uniformly cooperative with intraocular pressure measurement, and the often insidious and painless presentation of this problem. In our series, the detection of the elevated IOP occurred always on routine examination under anesthesia.

Rehabilitation of aphakia requires a coordinated team of low-vision expert ophthalmologists, optometrists, pediatricians, and most importantly the collaboration of the family. ${ }^{27}$ Aphakic spectacles or contact lenses were prescribed to our patients in order to address amblyopia, together with occlusion therapy when needed. ${ }^{27}$ Management of unilateral aphakia is more challenging as the use of contact lenses is mandatory to optimize development of useful vision.

This study has a number of limitations. It is a retrospective study, and this influences the inhomogeneous characteristics of the groups (stage $4 \mathrm{~B}$ vs. 5 , LSV vs. LV). Secondly, the relatively late timing of the surgery due to logistic issues despite prompt referral renders comparison with series wherein surgery was performed promptly difficult. The fact that some cases were operated upon earlier in Italy represented another limitation and, interestingly, this affected the visual and not the combined anatomical and visual outcome.
In conclusion, after a mean of 8.5 years followup, the anatomic and visual success rates following vitreoretinal surgery for ROP stage $4 \mathrm{~B}$ and 5 were encouraging for an interventional approach. Retinal reattachment allowed an achievement of better visual outcome as compared to the untreated natural history of advanced ROP related RD.

\section{REFERENCES}

1. Solebo AL, Rahi J. Epidemiology, aetiology and management of visual impairment in children. Arch Dis Child. 2014;99(4):375-379.

2. Quinn GE, Barr C, Bremer D, et al. Changes in course of retinopathy of prematurity from 1986 to 2013: Comparison of three studies in the United States. Ophthalmology. 2016;123(7):1595-1600.

3. Fierson WM, American Academy of Pediatrics Section on Ophthalmology, American Academy of Ophthalmology, American Association for Pediatric Ophthalmology, Strabismus, American Association of Certified Orthoptists. Screening examination of premature infants for retinopathy of prematurity. Pediatrics. 2013;131(1):189-195.

4. Repka MX, Tung B, Good WV, Capone A Jr., Shapiro MJ. Outcome of eyes developing retinal detachment during the Early Treatment for Retinopathy of Prematurity study. Arch Ophthalmol. 2011;129(9):1175-1179.

5. Seaber JH, Machemer R, Eliott D, Buckley EG, deJuan E, Martin DF. Long-term visual results of children after initially successful vitrectomy for stage $\mathrm{V}$ retinopathy of prematurity. Ophthalmology. 1995;102(2):199-204.

6. Capone A Jr., Trese MT. Stage 5 retinopathy of prematurity: Then and now. Retina. 2006;26(7):721-722.

7. Wu WC, Drenser KA, Lai M, Capone A, Trese MT. Plasmin enzyme-assisted vitrectomy for primary and reoperated eyes with stage 5 retinopathy of prematurity. Retina. 2008;28(3 Suppl):S75S80. 
8. El Rayes EN, Vinekar A, Capone A Jr. Three-year anatomic and visual outcomes after vitrectomy for stage $4 \mathrm{~B}$ retinopathy of prematurity. Retina. 2008;28(4):568-572.

9. Choi J, Kim JH, Kim SJ, Yu YS. Long-term results of lens-sparing vitrectomy for stages $4 \mathrm{~B}$ and 5 retinopathy of prematurity. Korean J Ophthalmol. 2011;25(5):305-310.

10. Maguire AM, Trese MT. Lens-sparing vitreoretinal surgery in infants. Arch Ophthalmol. 1992;110(2):284-286.

11. Trese MT. Surgical results of stage V retrolental fibroplasia and timing of surgical repair. Ophthalmology. 1984;91(5):461-466.

12. International Committee for the Classification of Retinopathy of Prematurity. The International Classification of Retinopathy of Prematurity revisited. Arch Ophthalmol. 2005;123(7):991-9999.

13. Karacorlu M, Hocaoglu M, Sayman Muslubas I, Arf S. Long-term functional results following vitrectomy for advanced retinopathy of prematurity. Br J Ophthalmol. 2017;101(6):730-734.

14. Gadkari S, Kamdar R, Kulkarni S, Kakade N, Taras S, Deshpande M. Vitreoretinal surgery for advanced retinopathy of prematurity: Presentation and outcomes from a developing country. Can J Ophthalmol. 2015;50(1):54-60.

15. Shah PK, Narendran V, Kalpana N, Tawansy KA. Anatomical and visual outcome of stages 4 and 5 retinopathy of prematurity. Eye (Lond). 2009;23(1):176-180.

16. Fuchino $\mathrm{Y}$, Hayashi H, Kono T, Ohshima K. Long-term follow up of visual acuity in eyes with stage 5 retinopathy of prematurity after closed vitrectomy. Am J Ophthalmol. 1995;120:308-316.

17. Trese MT, Droste PJ. Long-term postoperative results of a consecutive series of stages 4 and 5 retinopathy of prematurity. $O p h$ thalmology. 1998;105(6):992-997.

18. Cusick M, Charles MK, Agron E, Sangiovanni JP, Ferris FL 3rd, Charles S. Anatomical and visual results of vitreoretinal surgery for stage 5 retinopathy of prematurity. Retina. 2006;26(7):729-735.

19. Fielder A, Blencowe H, O'Connor A, Gilbert C. Impact of retinopathy of prematurity on ocular structures and visual functions. Arch Dis Child Fetal Neonatal Ed. 2015;100(2):F179-F184.

20. Palmer EA, Hardy RJ, Dobson V, et al. 15-year outcomes following threshold retinopathy of prematurity: Final results from the multicenter trial of cryotherapy for retinopathy of prematurity. Arch Ophthalmol. 2005;123(3):311-318.

21. Quinn GE, Dobson V, Barr CC, et al. Visual acuity of eyes after vitrectomy for retinopathy of prematurity: Follow-up at $51 / 2$ years. The Cryotherapy for Retinopathy of Prematurity Cooperative Group. Ophthalmology. 1996;103(4):595-600.

22. Fielder AR, Moseley MJ, Ng YK. The immature visual system and premature birth. Br Med Bull. 1988;44(4):1093-118.

23. Singh R, Reddy DM, Barkmeier AJ, Holz ER, Ram R, Carvounis PE. Long-term visual outcomes following lens-sparing vitrectomy for retinopathy of prematurity. Br J Ophthalmol. 2012;96(11):13951398.

24. Azuma N, Ishikawa K, Hama Y, Hiraoka M, Suzuki Y, Nishina S. Early vitreous surgery for aggressive posterior retinopathy of prematurity. Am J Ophthalmol. 2006;142(4):636-643.

25. Greven C, Tasman W. Scleral buckling in stages $4 \mathrm{~B}$ and 5 retinopathy of prematurity. Ophthalmology. 1990;97(6):817-820.

26. Kirwan C, O'Keefe M. Paediatric aphakic glaucoma. Acta Ophthalmol Scand. 2006;84(6):734-739.

27. Repka MX. Visual rehabilitation in pediatric aphakia. Dev Ophthalmol. 2016;57:49-68.

28. Mataftsi A. Incidence of and risk factors for postoperative glaucoma and its treatment in paediatric cataract surgery. Dev Ophthalmol. 2016;57:40-48.

29. Koc F, Kargi S, Biglan AW, Chu CT, Davis JS. The aetiology in paediatric aphakic glaucoma. Eye (Lond). 2006;20(12):1360-1365. 